\title{
Prevalence of Amlodipine Induced Gingival Enlargement - A Hospital Based Study
}

\author{
Latika Kothari' ${ }^{1}$ Pavan Bajaj², Priyanka Jaiswal ${ }^{3}$, Diksha Agrawal ${ }^{4}$ \\ ${ }^{1}$ Department of Periodontics, Sharad Pawar Dental College and Hospital, Datta Meghe Institute of \\ Medical Sciences (Deemed to be University), Sawangi (Meghe), Wardha, Maharashtra, India. \\ ${ }^{2}$ Department of Periodontics, Sharad Pawar Dental College and Hospital, Datta Meghe Institute of \\ Medical Sciences (Deemed to be University), Sawangi (Meghe), Wardha, Maharashtra, India. \\ ${ }^{3}$ Department of Periodontics, Sharad Pawar Dental College and Hospital, Datta Meghe Institute of \\ Medical Sciences (Deemed to be University), Sawangi (Meghe), Wardha, Maharashtra, India. \\ 4Department of Periodontics, Sharad Pawar Dental College and Hospital, Datta Meghe Institute of \\ Medical Sciences (Deemed to be University), Sawangi (Meghe), Wardha, Maharashtra, India.
}

\section{ABSTRACT}

\section{BACKGROUND}

Gingival enlargement is a complication associated with certain drugs (antihypertensives, anticonvulsants, and immunosuppressants). Amlodipine is a calcium antagonist and is structurally similar to nifedipine but pharmacodynamically different from it. The prevalence of amlodipine induced gingival enlargement is reported to be $3.3 \%$ which is lower than other calcium channel blockers. We wanted to determine the prevalence of amlodipine (calcium channel blocker) mediated gingival enlargement in patients undergoing treatment for hypertension for more than 6 months and explore how the patients' age, gender, treatment duration, and oral hygiene are related to gingival enlargement.

\section{METHODS}

Patients taking amlodipine were inspected for the presence of gingival enlargement using Bokenkamp and Bornhorst Index. Periodontal status of the patient was evaluated with Gingival Index, Plaque Index, Probing Pocket Depth and Clinical Attachment Loss.

\section{RESULTS}

In our study, 5 patients out of 108 patients on amlodipine were clinically diagnosed with enlargement, patients were prescribed amlodipine with a dosage of $2.5 \mathrm{mg}$ and $5 \mathrm{mg}$. Enlargement was seen in patients prescribed with a dosage of $5 \mathrm{mg} / \mathrm{day}$. Enlargement was found to begin at the interdental papilla and progress to marginal gingiva. The frequency of gingival enlargement induced by Amlodipine was found to be $4.6 \%$. The ratio of enlargement in males and females was $4: 1$. Plaque index and gingival index were found to be poor in patients with drug-induced enlargement.

\section{CONCLUSIONS}

Dentists and/or periodontists should be aware of the complications of certain systemic drugs such as calcium channel blockers so as to diagnose complications or problems like gingival enlargement.

\section{KEY WORDS}

Calcium Channel Blocker, Gingival Enlargement, Prevalence.
Corresponding Author:

Latika Kothari,

Intern,

Department of Periodontics,

Sharad Pawar Dental College and Hospital, Datta Meghe Institute of Medical Sciences

(Deemed to be University), Sawangi

(Meghe), Wardha, Maharashtra, India.

E-mail: latikakothari@gmail.com

DOI: $10.14260 / \mathrm{jemds} / 2020 / 529$

How to Cite This Article:

Kothari L, Bajaj P, Jaiswal $P$, et al. Prevalence of amlodipine induced gingival enlargement- a hospital based study. J Evolution Med Dent Sci 2020;9(34):24322435, DOI: 10.14260/jemds/2020/529

Submission 06-05-2020,

Peer Review 10-07-2020

Acceptance 17-07-2020,

Published 24-08-2020.

Copyright (C) 2020 JEMDS. This is an open access article distributed under Creative Commons Attribution License [Attribution 4.0 International (CC BY 4.0)] 


\section{BACKGROUND}

Gingival overgrowth or gingival enlargement is the term used for the medication induced gingival lesions previously known as gingival hyperplasia or hypertrophy. The terms used in the past did not precisely reflect a histological aspect of gingiva which has pharmacologically changed. ${ }^{1}$ gingival enlargement or hyperplasia is a benign painless condition characterized by enlargement of interdental papillae which ranges from mild to extremely severe conditions. It may cause aesthetic limitation, functional hindrances in speaking and swallowing and difficulty in mastication as a consequence of swelling of gingival margin and partial coverage of occlusal surfaces of teeth. ${ }^{2-4}$

Kimball in 1939 was the first to report drug-induced enlargement with long-term usage of Antiepileptic drug phenytoin. ${ }^{5}$ The prevalence of drug-induced gingival enlargement is $3-20 \%$. At present, there are more than 20 prescription medications inducing gingival hyperplasia. Anticonvulsants, calcium Channel blockers, immunosuppressants are three different classes of drugs found resulting in enlargement of gingiva.6,7 Although the primary targets of the drugs are different, the secondary target is the same i.e., gingival connective tissue. Therefore, it results in clinical and histopathological features being similar.8,9 The anticonvulsant (phenytoin) is being used since 1938 and its prevalence has ranged from 13-50 \%. Immunosuppressive drugs (cyclosporine A) have been used in the treatment of autoimmune disorder and the prevalence of cyclosporine $\mathrm{A}$ induced overgrowth is over $70 \%$ which depends on an individual's susceptibility. ${ }^{3}$

Calcium channel blocker is indicated for the management of cardiovascular disorder.10 Nifedipine is used in the treatment of hypertension and its prevalence ranges from 1483\%. ${ }^{11,12}$ Amlodipine (calcium channel blocker- third generation dihydropyridine) is used for the treatment of angina pectoris and hypertension. Amlodipine associated gingival enlargement was first reported by Ellis et al and Seymour et al. ${ }^{13,14}$ The prevalence of Amlodipine induced gingival enlargement is reported to be $3.3 \%$ which is lower than other calcium channel blockers. ${ }^{12}$ The aetiopathogenesis of gingival enlargement is not completely established due to which the management is primarily maintenance of an enhanced oral hygiene and resection of the enlarged gingival tissue.

\section{Objectives}

The aim of the study is to determine the prevalence of Amlodipine (calcium channel blocker) mediated gingival enlargement in the patients undertaking treatment for hypertension for more than 6 months and to explore how the patients' age, gender treatments duration and oral hygiene is related to gingival enlargement.

\section{METHODS}

This is a Cross-Sectional study which is carried out in the Department of Periodontics and General Medicine. Based on previous studies, sample size of 108 was calculated. Patients who had undergone periodontal treatment within the 6 months prior to the initiation of the study; with concomitant systemic disorders known to affect the gums (such as diabetes, leukemia, or immunodeficiency states); or taking anticonvulsants drugs, other agents associated with gingival enlargement (e.g., phenytoin or cyclosporine) and pregnant females were excluded from the study. Informed consent is taken from the patients prior to the conduction of the study. Clearance from the ethical committee is also taken prior to the conduction of study.

Patients under anti-hypertensives - Amlodipine are examined for the presence of gingival enlargement using Bokenkamp and Bornhorst Index given in 1994.13 The gingival index was also evaluated using Loe and Sillness gingival index $-1963.14$

- Grade 0- No signs of gingival enlargement

- Grade 1 - Enlargement confined to interdental papilla

- Grade 2 - Enlargement involves papilla and marginal gingiva.

- $\quad$ Grade 3 - Enlargement covers three quarters or more of the crown.

- $\quad$ Plaque index was evaluated using Sillness and Loe plaque index in 1964.15

- Probing pocket depth was calculated from the margin of the gingival to the base of the pocket and clinical attachment loss (CAL) was calculated from the cementoenamel junction to the base of the pocket.

\section{Statistical Analysis}

"All statistical analysis was performed using SPSS version 13.0 for Windows (SPSS Inc., Chicago, Illinois, USA). Means and standard deviation were calculated for all the variables. The difference in proportions was calculated using Chi-square test. The results were considered to be statistically significant if the $\mathrm{p}<0.05^{\prime \prime}$

\section{RESULTS}

A total of 108 patients participated in the study. No difference for age distribution or duration of drug therapy was evident. Mean age of the patients was $61.12 \pm 10.12$ years and consisted of 26 females and 82 males [Table 1] [Graph 1]. Patients in the study population were taking amlodipine. Of the 108 patients taking Amlodipine 5 patients presented with gingival enlargement. Out of these 5 Patients presenting with enlargement 4 were male and 1 was female.

The bivariate analysis in patients with and without overgrowth with respect to quantitative data (GI, PI, PPD, CAL) showed no significant association between any variable. There was no correlation between the dosage of amlodipine and duration of intake of amlodipine with gingival enlargement.

Although there wasn't any statistically significant difference between patients with overgrowth and without overgrowth with regards to the plaque, calculus, and gingival indices, scores were moderately high for both groups of patients [Table 2] 


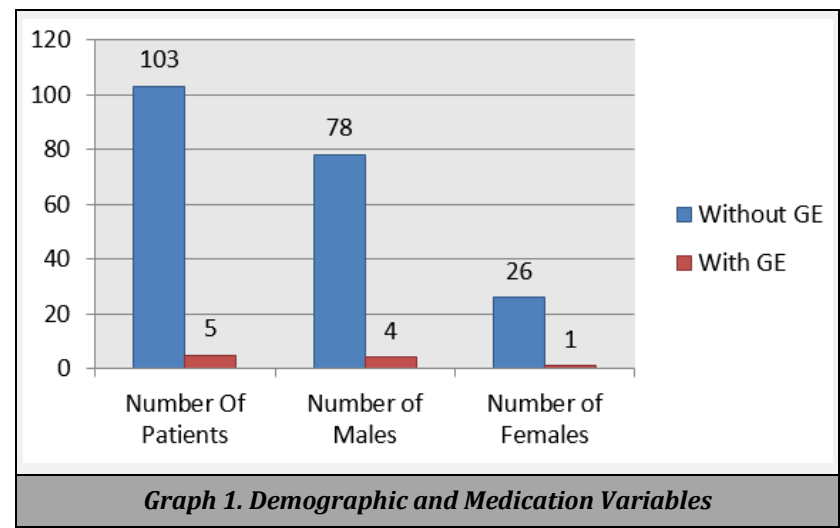

\begin{tabular}{|cc|}
\hline Number of Patients & 108 \\
Number of males & 82 \\
Number of females & 26 \\
Age (Mean \pm SD) & $61.12 \pm 10.12$ \\
Dosage & $5 \mathrm{mg}$ and $2.5 \mathrm{mg}$ \\
\hline Number of Patients with gingival enlargement & 5 \\
\hline Table 1 Demographic and Medication Variables \\
\hline
\end{tabular}

\begin{tabular}{|cccc|}
\hline Variables & $\begin{array}{c}\text { Without Gingival } \\
\text { Enlargement }\end{array}$ & $\begin{array}{c}\text { With Gingival } \\
\text { Enlargement }\end{array}$ & P - Value \\
GI & $2.16 \pm 0.20$ & $2.36 \pm 0.11$ & 0.06 \\
PI & $2.11 \pm 0.31$ & $2.14 \pm 0.26$ & 0.80 \\
PPD & $3.41 \pm 0.84$ & $4.52 \pm 0.95$ & 0.055 \\
CAL & $4.06 \pm 0.92$ & $4.72 \pm 0.28$ & 0.12 \\
\hline \multicolumn{4}{c}{ Table 2 Periodontal Variables } \\
\hline
\end{tabular}

\section{DISCUSSION}

Gingival enlargement is a complication associated with certain drugs (antihypertensives, anticonvulsants, and immune suppressants).6,7 The drug identified as a causative agent of enlargement of gingiva in this study is Amlodipine. Amlodipine is a calcium antagonist and is structurally similar to nifedipine but pharmacodynamically different from it. Drug-induced gingival enlargement initiates within three months of the drug therapy commencing at the interdental papilla. It is known to occur at a dose of $10 \mathrm{mg} /$ day however some cases of enlargement have also been reported at $5 \mathrm{mg} /$ day.

In our study, 5 patients out of 108 patients on Amlodipine were clinically diagnosed with enlargement. As it was a hospital-based study-patients were prescribed Amlodipine with a dosage of $2.5 \mathrm{mg}$ and $5 \mathrm{mg}$. Enlargement was seen in patients prescribed with a dosage of $5 \mathrm{mg}$ /day. Enlargement was found to begin at the interdental papilla and progress to marginal gingiva. Gingival enlargement was assessed on the basis of index given by Bokenkamp A et al. ${ }^{13}$ of the 5 patients under study 3 patients were clinically diagnosed of having grade 3 enlargements, 1 patient presented with grade 2 enlargement and 1 patient presented with grade 1 enlargement at a dose of $5 \mathrm{mg} /$ day. The frequency of gingival enlargement induced by Amlodipine was found to be $4.6 \%$. The results were in accordance with Jorgensen and higher than Ellis et al but lower than Seymour and Gopal.16-19

The number of males in the study was 82 and females were 26. Of the 5 patients presenting with enlargement 4 were males and 1 was female. The ratio of enlargement in males and females was 4:1. This was in accordance with the study of Sucu et al and Prishant et al, where they reported that gingival enlargement is 3.3 times more common in men than in women. ${ }^{19,20}$ Many studies reported that $5 \mathrm{mg}$ once daily dosage of amlodipine cannot induce gingival enlargement even if consumed for 6 months or more. Gingival enlargement is evident only at a dose of $10 \mathrm{mg} /$ day. ${ }^{17,18}$ However, in present study, even $5 \mathrm{mg}$ once daily dosage of amlodipine consumed for 3 months caused gingival enlargement. Patients with Drug Induced gingival enlargement have poor Plaque index and gingival index as compared to the patients without enlargement. Therefore, one can conclude that amlodipine induced enlargement is multifactorial in nature and also that the severity is influenced by the dosage, blood levels of amlodipine and oral hygiene status (plaque and calculus), gingival inflammation of any aetiology and genetic factors (fibroblasts with an abnormal susceptibility to the drug). ${ }^{4}$

The pathogenesis of the drug-induced enlargement is not fully known or understood. It may be due to inflammatory or non-inflammatory mechanisms. ${ }^{4}$ it is exacerbated by plaqueinduced gingival inflammation and also the fact that edentulous patients do not show any signs of enlargement draws us to a conclusion that it is most probably related to inflammatory factors related to dentition. ${ }^{12}$

Ongoing studies on the aetiopathological mechanism of amlodipine induced gingival enlargement are concentrating on the direct and indirect effects of such drugs on gingival fibroblast metabolism. Due to a very less number of patients prescribed with amlodipine manifest gingival enlargement, it might be hypothesized that enlargement might be due to higher susceptibility of fibroblast to amlodipine. It also has been hypothesized that different subsets of this fibroblast existing in a susceptible or resistant individual will lead to amlodipine induced gingival enlargement. ${ }^{21}$

Treatment is mainly drug substitution and adequate control of local inflammatory factors. ${ }^{21}$ When both these measures fail to cause resolution, surgery is carried out. ${ }^{20}$ Surgery is performed for both cosmetic needs and function. ${ }^{22}$ 24 Most cases of amlodipine induced gingival enlargement requires surgical procedure. ${ }^{25}$

\section{CONCLUSIONS}

Dentists and/or periodontists should be aware of the complications of certain systemic drugs such as calcium channel blockers so as to diagnose complications or problems like gingival enlargement. The first and foremost treatment should be drug substitution and it should be followed by diligent plaque control measures. If at all these measures fail to resolve gingival enlargement, surgical correction should be undertaken.

Financial or Other Competing Interests: None.

\section{REFERENCES}

[1] Rees TD, Levine RA. Systemic drugs as a risk factor for periodontal disease initiation and progression. Compendium 1995;16(1):20-42. 
[2] Nyska A, Shemesh M, Tal H, et al. Gingival hyperplasia induced by calcium channel blockers: mode of action. Med Hypotheses 1994;43(2):115-8.

[3] Lafzi A, Farahani RMZ, Shoja MAM. Amlodipine-induced gingival hyperplasia. Med Oral Patol Oral Cir Bucal 2006;11(6):E480-2.

[4] Joshi S, Bansal S. A rare case report of amlodipine-induced gingival enlargement and review of its pathogenesis. Case Rep Dent 2013;2013:1-3.

[5] Pradhan S, Mishra P. Gingival enlargement in antihypertensive medication. J Nepal Med Assoc 2009;48(174):149-52.

[6] Dongari-Bagtzoglou A. Drug-associated gingival enlargement. J Periodontol 2004;75(10):1424-31.

[7] Garzino-Demo P, Carbone M, Carrozzo M, et al. An increase in gingival volume induced by drugs (phenytoin, cyclosporine and calcium antagonists). A review of the literature. Minerva Stomatologica 1998;47(9):387-98.

[8] Bork K, Hoede N, Korting GW, et al. Diseases of the oral mucosa and the lips. $2^{\text {nd }}$ edn. W. B. Saunders Company 1996:310-2.

[9] Trackman PC, Kantarci A. Connective tissue metabolism and gingival overgrowth. Crit Rev Oral Biol Med 2004;15(3):165-75.

[10] Acharya S, Shukla S, Wanjari A. Subclinical risk markers for cardiovascular disease (CVD) in metabolically healthy obese (MHO) subjects. J Clin Diagn Res 2019;13(6):OC16.

[11] Papalkar P, Kumar S, Agrawal S, et al. Heterotaxy syndrome presenting as severe pulmonary artery hypertension in a young old female: case report. Journal of Gerontology and Geriatrics 2018;66(2):59-61.

[12] Livada R, Shiloah J. Calcium channel blocker-induced gingival enlargement. J Hum Hypertens 2014;28(1):10-4.

[13] Bökenkamp A, Bohnhorst B, Beier C, et al. Nifedipine aggravates cyclosporine A-induced gingival hyperplasia. Pediatr Nephrol 1994;8(2):181-5.
[14] Löe H, Silness J. Periodontal disease in pregnancy I. Prevalence and severity. Acta Odontol Scand 1963;21(6):533-51.

[15] Silness J, Löe H. Periodontal disease in pregnancy II. Correlation between oral hygiene and periodontal condition. Acta Odontol Scand 1964;22(1):121-35.

[16] Ellis JS, Seymour RA, Steele JG, et al. Prevalence of gingival overgrowth induced by calcium channel blockers: a community-based study. J Periodontol 1999;70(1):63-7.

[17] Seymour RA, Thomason JM, Ellis JS. The pathogenesis of drug-induced gingival overgrowth. J Clin Periodontol 1996;23(3 Pt 1):165-75.

[18] Jorgensen MG. Prevalence of amlodipine-related gingival hyperplasia. J Periodontol 1997;68(7):676-8.

[19] Gopal S, Joseph R, Santhosh VC, et al. Prevalence of gingival overgrowth induced by antihypertensive drugs: a hospital-based study. J Indian Soc Periodontol 2015;19(3):308-11.

[20] Sucu M, Yuce M, Davatoglu V. Amlodipine-induced massive gingival hypertrophy. Can Fam Physician 2011;57(4):436-7.

[21] Grover V, Kapoor A, Marya CM. Amlodipine induced gingival hyperplasia. J Oral Health Comm Dent 2007;1:1922.

[22] Triveni MG, Rudrakshi C, Mehta DS. Amlodipine induced gingival overgrowth. J Indian Soc Periodontol 2009;13(3):160-3.

[23] Amit B, Shalu BV. Gingival enlargement induced by anticonvulsants, calcium channel blockers and immunosuppressants: a review. IRJP 2012;3(7):116-9.

[24] Marshall RI, Bartold PM. A clinical review of drug-induced gingival overgrowth. Oral Surg Oral Med Oral Pathol 1993;76:543-8.

[25] Lombardi T, Fiore-Donno G, Belser U, et al. Felodipine induced gingival hyperplasia: a clinical and histologic study. J Oral Pathol Med 1991;20(2):89-92. 